\title{
LEITURAS POÉTICAS NA CONSTRUÇÃO DA SUBJETIVIDADE DOS ALUNOS DO ENSINO MÉDIO
}

\author{
Cynthia Agra de Brito Neves
}

\begin{abstract}
RESUMO
Este artigo analisa práticas de leitura de poesias em voz alta em salas de aula do ensino médio no Brasil e na França. Ao se deixarem tocar pelas leituras poéticas, os alunos (re)encontram sua posição de sujeito, sua dignidade, sua condição humana, sua cidadania, um trabalho quase psicanalítico na (re)construção de si. Enfim, os alunos-leitores de poesias, ao (se)lerem, (se)dizerem, (se) escreverem, colocam-se no mundo.
\end{abstract}

PALAVRAS-CHAVE: letramento literário; gêneros poéticos; leitura subjetiva.

"As poesias na escola podem ainda oferecer às poesias e aos alunos a oportunidade de (se) ler, de (se) dizer, de (se) escrever. As poesias se fazem a cada dia na leitura de todos, na fala de cada um, pois ninguém pode evitar 'a rima e a vida'."

(Marie-Claire Martin e Serge Martin) $^{1}$

\section{Introdução}

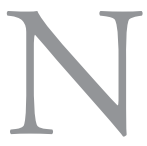

as últimas décadas a relação entre leitura literária e educação anda estremecida e não faltam críticas às práticas escolares no que diz respeito ao ensino-aprendizagem de literatura. É comum ouvir entre

1 "Les poésies à l'école peuvent encore donner l'occasion aux poésies et aux élèves de (se) lire, de (se) dire, de (s') écrire. Les poésies se font chaque jour dans la lecture de tous, dans la parole de chacun, car aucun ne 'la rime et la vie’." (tradução nossa). In: Martin, Marie-Claire \& Martin, Serge. Les poésies, l'école. 1er. peut éviter édition. Paris: Presses Universitaires de France, 1997, p. 138. 
os educadores, em especial os professores de Língua Portuguesa, as reclamaçôes acerca das dificuldades de seus alunos em ler e interpretar textos, refletir criticamente e, ainda, escrever sobre alguma temática proposta obedecendo a determinado gênero discursivo/textual. Em se tratando da leitura e interpretação de textos de gêneros literários, sobretudo os poéticos, as dificuldades parecem alçar voo - lamentam constantemente os docentes do Ensino Médio.

A invasão da teoria dos gêneros na escola acabou contribuindo ainda mais para esse distanciamento, uma vez que as práticas de leitura e escrita literárias passaram a ser vistas como práticas não sociais, e que, portanto, não deveriam ser escolarizadas - critica, com razão, Rildo Cosson (2011). De fato, é possível dizer, em comum acordo com Roxane Rojo (2005) e Luiz Antônio Marcuschi (2008), que essa abordagem de ensino de Língua Materna (doravante LM) baseada na teoria dos gêneros se tornou moda no Brasil e segue as diretrizes curriculares dos autores da Universidade de Genebra, Bernard Schwneuly e Joaquim Dolz (2004), expostas em Gêneros orais e escritos na escola, os quais foram revozeados em nossos Parâmetros Curriculares Nacionais (Pcns).

Hoje, as instituiçóes escolares, tanto públicas quanto particulares, têm optado por ensinar LM trabalhando em sala de aula com diversos tipos de linguagem e diferentes gêneros do discurso, buscando assim aproximar-se da realidade de mundo de leitura para o qual os alunos contemporâneos estáo atentos: uma leitura rápida, dinâmica, veloz; de uma escrita diluída, dissipada em jornais, revistas, cinemas e, principalmente, na internet.

É por meio da tela de computadores, de celulares, de smartphones, de tablets que o aluno do século XXI lê textos do discurso eletrônico, os quais circulam na mídia virtual (hipertextos, e-mails, blogs, chats, sites, homepages etc.) e, desse modo, acrescenta Roger Chartier (1994, p. 103), "pode submeter os textos a múltiplas operaçóes (pode indexá-lo, anotá-lo, copiá-lo, desmembrá-lo, recompô-lo, deslocá-lo etc.); mais do que isso, ele pode se tornar seu co-autor" ou "lautor", como prefere Rojo (2013, p. 20). O letramento passou a ser multimodal, para usar outro termo também em moda.

Reconheço sem pesar, e em comum acordo com Fábio Akcelrud Durão (2012), que há tempos que a escola não forma mais o homme de lettres, até porque a internalização da letra já não é mais possível como nos tempos do século XIX, quando a cultura era muito mais elitizada do que hoje e de acesso mais difícil, um "privilégio de classe", reconhece o autor. Esse afastamento 
da letra, justifica Durão (2012), é natural diante do domínio da imagem, da preponderância da televisão, do vídeo game, sem falar da própria internet e, metonimicamente, do facebook, que funcionam atualmente como veículos de socialização dos indivíduos ${ }^{2}$. Na prática educativa, a política neoliberal aliada à ideologia da inclusão digital coloca os computadores acima dos livros, assim, dentro dessa lógica, os estudos literários parecem ser um mero adorno, algo inútil, um privilégio de classe sem relevância real, e que podem, portanto, ser suprimidos - adverte-nos Durão (2012).

Cosson (2006) reconhece essa "arrogância" com relação ao saber literário, por isso trata de defender o letramento literário e a inserção do ensino de literatura na grade curricular da Educação Básica. Segundo o autor, "alguns acreditam que se trata de um saber desnecessário. Para esses, a literatura é apenas um verniz burguês de um tempo passado, que já deveria ter sido abolido das escolas. Eles [...] pensam que não precisam aprender literatura porque já conhecem e dominam tudo o que lhes interessa”. (Cosson, 2006, p. 10).

"Para continuar vivos, os estudos literários têm que mudar e ao mesmo tempo permanecer o que são" - conclui Durão (2012, p. 193), para depois reivindicar que "é necessário que os estudos literários assumam o desafio de incorporar em seu bojo os novos objetos" (2012, p. 197). Isto é, que nas práticas escolares, o letramento literário esteja democraticamente presente ao lado dos novos letramentos digitais e multiletramentos, para que os gêneros literários e poéticos possam igualmente contracenar com a diversidade de textos e gêneros multimodais/multissemióticos e multi/hipermidiáticos cada vez mais (oni) presentes na contemporaneidade. Coloco-me, portanto, a favor do letramento literário, em especial, do ensino dos gêneros poéticos.

Este artigo é parte de minha pesquisa de doutorado, concluído em 2014, no Instituto de Estudos da Linguagem, na Universidade Estadual de Campi-

2 O autor aproveita-se desse momento para tecer, em nota de rodapé, sua crítica, aqui muito bem-vinda, uma vez que aquece a polêmica: "É muito comum o argumento de que a internet pode funcionar como uma forma de introdução à literatura. Até que estudos quantitativos e qualitativos convincentes sejam apresentados, permaneço cético. A dinâmica de leitura e de escrita na tela é completamente diferente daquela do papel (ainda que o Word o imite); tendo a pensar que não é frutífero chamar de literatura aquilo que se produz com esse nome na internet, o que não é um julgamento de valor. Simplesmente, o tipo de leitura de um hipertexto ou mesmo de um site difere tanto da [leitura] de um romance ou poesia, que mereceria outro nome”. (Durão, 2012, p. 201-202) 
nas (Iel/Unicamp), em que procuro investigar as formas como "as poesias" ou "os gêneros poéticos" - mantendo sempre o plural, para levar em conta sua plurissignificação (presente na forma clássica de um soneto, mas também em grafites pelos muros das cidades) - têm circulado em salas de aula do Ensino Médio no Brasil e na França. Trata-se, portanto, de um estudo contrastivo, que tem como foco o ensino-aprendizagem da literatura, sobretudo, das poesias, a partir da observação do trabalho de docentes brasileiros e franceses com textos poéticos e das formas como os alunos reagem a esses textos nas dinâmicas em sala de aula. Também foram contrastados os currículos de ambos os países, os materiais didáticos utilizados, bem como as avaliaçóes nacionais: o Exame Nacional de Ensino Médio (Enem) brasileiro e o Baccalauréat francês (conhecido como bac).

$\mathrm{O}$ interesse pela pedagogia francesa deve-se à sua influência histórica no sistema educacional brasileiro, sobretudo na área de ensino de língua e literatura. O Colégio Pedro II, as Congregaçóes Maristas, as Escolas Normais e os Liceus são exemplos de que as raízes francesas ficaram-se no solo de nossa educação desde meados do século XIX. Em 2011, tornou-se possível concretizar essa pesquisa em território francês, graças à oportunidade de participar do Cedilit (Centre de Recherche en Didactique de la Littérature ${ }^{3}$ ), na Université Stendhal Grenoble 3, em Grenoble, região de Rhône-Alpes, na França.

Além dos encontros e discussóes com esse grupo, acompanhei 40 horas de aulas de língua e literatura francesas em classes de secondes générales, de premières e de terminale, em dois lycées ${ }^{4}$ de Grenoble: o Champollion (com Mme. Sarah Blancard) e o Marie Curie (com Mme. Valéry Gardey). No Brasil, de 2010 a 2013, observei 50 horas de aulas de língua e literatura maternas em classes do primeiro, segundo e terceiro anos do ensino médio, em duas escolas privadas

3 Centro de Pesquisa em Didática da Literatura.

4 Na França, o lycée corresponde ao nosso ensino médio, que também tem a duração de três anos, sendo o primeiro ano chamado de seconde générale, o segundo ano de première, e o terceiro ano de terminale. No primeiro ano do ensino médio, ou seja, no seconde générale, os alunos têm disciplinas mais gerais e, somente a partir do segundo ano, do première, é que optam por fazer o ensino médio scientifique (S), économique et social (ES), ou littéraire (L), o que significa diferenças de cargas horárias entre as disciplinas e de peso (coeficientes) nas avaliaçóes do Baccalauréat (o bac), o exame nacional francês, realizado em duas etapas: ao final do première e do terminale. É esse exame que garante o ingresso dos alunos nas universidades francesas, tal qual tem se configurado o nosso Enem no Brasil. 
(25 horas/aula) e uma escola da rede pública (25 horas/aula) do interior de São Paulo, cujos nomes são omitidos por questôes éticas de pesquisa ${ }^{5}$. Ao todo, foram 90 horas de aulas assistidas, in loco, em território nacional e francês.

Participei, nos respectivos tempos e espaços, das atividades envolvendo poesias e, como pesquisadora-observadora, sob uma perspectiva qualitativa, interpretativista e subjetivista (Moita Lopes, 1994), recolhi dados de interesse para a composição do meu "diário de classe", o qual serviu como um dos objetos de análise da tese. Para este trabalho, contudo, como parte do corpus selecionado, escolhi algumas das anotaçóes e críticas que fiz, atentando especialmente para as práticas de leituras subjetivas de poesias em contexto escolar francês e no ensino médio brasileiro: por vezes de maneira tão avessa; outras, de modo muito semelhante.

\section{Entre os muros da escola ${ }^{6}$ : as leituras poéticas reduzidas a análi- ses formais e à busca pelas figuras de estilo}

Em um espaço institucional até hoje tão burocrático, poderoso e controlador de discursos (Foucault, 2006) como é a escola, é difícil imaginar o incentivo a atividades que remetam os alunos à alegria (Snyders, 1993) e ao prazer do texto (Barthes, 2006), principalmente ao prazer das leituras poéticas, as quais, muitas vezes e sob diversas formas, são castradas pela instituição escolar.

Os professores cujas aulas acompanhei aqui e lá são sugados por esse sistema escolar e a prova disso se dá quando submetem suas didáticas de ensino de literatura aos ditames do vestibular e do Enem, no caso do Brasil, e ao bac, no caso da França. Esses exames nacionais, em geral, têm ditado as regras ao funcionamento didático do ensino médio em território nacional e francês,

5 Seguindo a recomendação do Comitê de Ética da UnicAmp, os nomes dos professores e dos colégios brasileiros envolvidos nesta pesquisa foram omitidos. Essa preocupação não foi necessária em território francês, por isso, mantive ao longo deste artigo os nomes franceses e omiti os nacionais. No Brasil, utilizei as nomenclaturas P1, P2, P3 e P4 para me referir aos professores-sujeitos da pesquisa; as letras $\mathrm{A}$ e $\mathrm{B}$ para me dirigir aos colégios particulares, e a letra $\mathrm{C}$ para a escola pública. Os nomes dos alunos brasileiros e franceses, menores de idade, também foram forjados com as supostas iniciais de seus nomes. Justifico, ainda, que escolas e professores envolvidos na pesquisa autorizaram, oficialmente, minha presença em suas salas de aulas, assinando os documentos de termo de consentimento livre esclarecido.

6 Faço aqui uma alusão ao filme do cineasta francês Laurent Cantet, Palma de Ouro em Cannes, 2008. 
sobretudo no que rege o ensino-aprendizagem de língua e literatura nos dois países em questão. Ao acompanhar as sequências didáticas (doravante SD) poéticas cá e lá, pude perceber a preocupação constante com o exame nacional tanto nos discursos dos docentes, quando decidem ensinar este ou aquele poeta; quanto no interesse dos discentes pelo assunto tratado na disciplina.

$\mathrm{Na}$ França, ensina-se o aluno a lecture expressive ${ }^{7}$, isto é, a leitura em voz alta, respeitando as liaisons $^{8}$ e os enjambements ${ }^{9}$, bem como se treina a produção escrita do commentaire composé10 - tudo mensurável pelas exigências do bac. No ensino médio brasileiro, não se pratica a leitura poética em voz alta, uma vez que os vestibulares e o Enem são avaliaçóes estritamente escritas. Por outro lado, desde o primeiro ano ensinam-se, de modo insistente, as regras de metrificação, a escansão, as rimas, enfim, aspectos formais do texto poético cobrados em questôes de alguns vestibulares.

No país da Belle Époque, acompanhei um módulo inteiro de trabalho com poesias que iam do simbolismo ao surrealismo nas classes de secondes générales do lycée Champollion. O objetivo principal daquela SD, esclareceu-me a professora Mme. Blancard, era a leitura completa de Les Fleurs du Mal, de Charles Baudelaire. Os alunos teriam que ler a obra poética em casa e, em sala de aula, a professora retomaria a leitura de alguns poemas por ela selecionados. Após a leitura de cada poema, a professora selecionava algumas questóes de interpretação de texto propostas pelo livro didático, os alunos respondiam e seguia-se a correção do exercício.

Um dos primeiros poemas trabalhados foi "Élévation". Logo após a sua leitura, Mme. Blancard pergunta se alguém tem dúvidas acerca do vocabulário

7 Leitura expressiva.

8 As liaisons são ligaçóes feitas somente na língua oral entre o fim de uma palavra (geralmente quando esta termina com uma consoante) e o início de outra (geralmente quando esta começa com uma vogal ou um " $h$ " mudo). Elas podem ser feitas tanto obrigatoriamente quanto facultativamente, mas em ambos os casos as duas palavras são unidas como se fossem uma só.

9 De acordo com o dicionário Houaiss, o enjambement - termo que importamos da França - é "a partição de uma frase no final de um verso ou uma estrofe, sem respeitar as fronteiras dos sintagmas, colocando um termo do sintagma no verso anterior e o restante no verso seguinte; debordamento, cavalgamento, encadeamento, quebra de verso, transbordamento [...]". (Houaiss, p. 1.152)

10 O commentaire composé é um tipo de texto de gênero argumentativo em que o aluno aprende a dissertar sobre um determinado autor e sua respectiva obra, apontando características estilísticas e temáticas destes. 
do poema. Em seguida, explica o spleen [tédio] e o ideal [ideal], no poema "Le Spleen et l'Ideal”, e já lança à classe uma série de perguntas abertas do tipo: "Qual é a forma do poema?”, "Quantas sílabas?”, "Qual é a rima?”, "Campos lexicais". Somente ao final é que se preocupa em explorar a polissemia do título do poema: Élévation physique [Elevação física], Élévation spirituelle / mentale [Elevação espiritual / mental], Sens religieux = l'élévation de l'hostie [Sentido religioso = elevação da hóstia] - e pede que os alunos releiam o poema em busca desses sentidos escritos como espécie de roteiro na lousa.

Em outra aula, após a leitura do mesmo poema baudelaireano, a professora aponta para anáfora em Par dela [Além de], expressão que se repete nos versos 3 e 4; chama a atenção para o uso do imperativo no verso 9: Envole-toi [Voa (tu)]; explica a ideia metonímica no verso 15: Heureux celui qui peut d'une aile vigoureuse [Feliz aquele que (pode) de asa vigorosa (lançar-se)] = metonymie de l'oiseau / de l'ange [metonímia de pássaro e anjo], e só então fala da "transcendência" proposta nesse verso. Pergunta à classe qual é a figura de estilo contida ali e anota a resposta do aluno na lousa: "aliteração" em "l" para mostrar a liberdade, a ligeireza do espírito. Explora a questão da "dualidade" para explicar a "antítese" e o "paradoxo"; solicita que seus alunos identifiquem no poema exemplos de enjambements, explica as figuras de linguagem e depois as localiza nos versos com o auxílio dos alunos.

As perguntas propostas por Mme. Blancard já indicam a preocupação em explorar os aspectos formais do poema, a atenção exagerada às figuras de linguagem. A ideia de elevação como libertação, a transcendência espiritual, a fuga do mundo real, o nirvana... todos esses aspectos temáticos que envolvem o poema "Élévation" são interpretados e analisados à luz de uma explicação $a$ priori formal do poema.

A crítica de Michèle Petit a esse tipo de ensino é bastante pertinente:

E privilegiou-se uma concepçáo instrumentalista, formalista, inteiramente ao lado da maestria do texto - inspirada na linguística estrutural e na semiótica, depois na nova-retórica [...]. O 'texto' literário tornou-se uma máquina que funciona - supóe-se que o leitor adquire um saber-fazer técnico, as ferramentas capazes de fazê-lo funcionar - como uma 'forma de discurso' entre outras [...]. Curiosamente, quanto mais a 
escola se abria a categorias sociais afastadas da cultura letrada, mais se impunha um jargão e técnicas de extrema sofisticação, emprestadas da crítica textual, das teorias da enunciação, da retórica [...]. E como diz François Bon, [...] é possível evidentemente questionar se é com esse tipo de conhecimento que se lê ou se escreve. (Petit, 2002, p. 127-128) ${ }^{11}$.

De fato, jargóes e técnicas não ensinam a ler nem a escrever, e muito menos trabalham a subjetividade de um aluno como sujeito leitor de poesias, tal como entendo que deve ser o papel da escola. De acordo com Annie Rouxel (2004, p. 149), é desse modo que: "o ensino médio transformou a leitura em uma prática formal, dissecante, mesmo que se pretenda desenvolver a sensibilidade dos alunos"12.

No Brasil, a didática se faz de modo semelhante, uma vez que nossos livros didáticos de língua e literatura maternas do ensino médio insistem em propor exercícios que, como observa Joaquim Brasil Fontes (1999), forçam o aluno a identificar em fragmentos textuais, sobretudo em poesias, as figuras de estilo, como forma de reconhecer os recursos estilísticos que caracterizariam este ou aquele autor, esta ou aquela escola literária. Não apenas o livro didático supervaloriza as figuras escondidas nos discursos, como a própria estratégia de aula do professor é moldada dessa forma, amarrada a questóes que exploram identificaçóes e classificaçóes como, por exemplo, de figuras ou funções de linguagem.

Foi o que observei em uma dinâmica de aula a que assisti em uma escola da rede privada de ensino (Colégio B), na qual o professor (P2) propôs que os

11 "Et l'on a privilegié une conception instrumentale, formaliste, entièrement du côté de la maîtrise du texte - inspiré de la linguistique structurale et de la sémiotique, puis d'une neo-rhétorique [...]. Le 'texte' littéraire est devenu une machine qui fonctione le lecteur étant supposé acquérir le savoir-faire technique, les outils à même de le faire fonctionner - puis une 'forme de discours' parmi d'autres. [...] Curiousement, plus l'école s'ouvrait à des catégories socials éloignées de la culture lettrée, plus s'y imposaient un jargon et des techniques d'une extrême sophistication, empuntés à la critique textuelle, aux theories de l'énonciation, à la rhétorique [...]. Et, comme le dit François Bon, [...] on peut évidemment se demander si c'est avec cela qu'on lit ou qu'on écrit.» (tradução nossa).

12 “[...] le lycée a tranformé la lecture en une pratique formelle, desséchante, lors même qu’il entend développer la sensibilité des élèves.» (tradução nossa). 
alunos do segundo ano do ensino médio fizessem os exercícios da apostila referentes ao poema "Antífona", de Cruz e Souza. As questôes de interpretação de texto do referido poema, que se apresenta fragmentado no material didático, obedeciam à seguinte ordem: "O poema apresenta regularidade métrica? Qual a distribuição de rimas?”; "Localize no poema termos do vocabulário litúrgico, religioso. Que atmosfera geral esses termos conferem ao poema?”; e por fim, uma pergunta sobre função da linguagem, seguida de interrogaçóes como: "se o poema é metalinguistico, quais são as imagens visuais do poema; dê exemplos de imagens olfativas e sonoras; fale sobre o emprego das reticências".

Em todo o módulo de exercícios não havia uma só questão que remetesse ao conteúdo do poema simbolista. As imagens visuais, olfativas e sonoras são claramente alusôes à presença das sinestesias, ou seja, os exercícios têm como finalidade, via de regra, a análise e o reconhecimento formal de aspectos do poema. $\mathrm{O}$ professor, obrigado a seguir a apostila, não consegue escapar dessa armadilha estruturalista. P2 parece não se incomodar com isso, ao contrário, sempre lê o poema em voz alta e diz que é importante "sentir o poema" na leitura, entretanto, a primeira pergunta que lança à classe ao terminar de ler é se o texto é um soneto ou não. Em uma aula, chegou a confessar que gosta de olhar primeiro para a forma do poema - e ensina isso aos alunos - para depois trabalhar seus outros aspectos que, pelo visto, ficam em segundo plano.

Vê-se, pois, que em ambos os contextos escolares, realiza-se um tipo de leitura de decodificação, a qual Ana Elvira Luciano Gebara (2002) chama de "leitura eferente", e não uma "leitura estética", que leva em conta o prazer das leituras poéticas ou o gosto subjetivo pelas poesias. Buscar no poema de Cruz e Souza os efeitos sinestésicos é um exercício interessante, desde que não seja simplesmente para decodificar o poema e classificá-lo como simbolista, como constatei naquela aula.

Para Tzvetan Todorov (2012), o mea culpa deve-se ao ensino universitário, que ora privilegia o estruturalismo, ora o niilismo, ora o solipsismo, "assassinando", desse modo, a literatura. O autor francês coloca-se, nesse sentido, como inimigo do "didatismo", pois acredita que o conhecimento de literatura não é um fim em si mesmo, mas uma das vias régias que conduzem à realização pessoal de cada um, o que poderá ter como consequência o amor à literatura. 
No senso comum, fala-se em crise da leitura na escola e se lamenta frequentemente a não formação de alunos-leitores competentes. Peço licença (poética, talvez) para discordar dessa visão pessimista e destaco, neste trabalho, alguns momentos que experimentei em salas de aula e que demonstram exatamente o contrário disso. Os alunos do ensino médio procuram muitas vezes escapar dessa "prisão" formal - e, por extensão, institucional - descrita anteriormente, desviando o foco da aula para aquilo que lhes é de interesse subjetivo, seja quando realizam uma leitura inesperada das poesias e, por isso mesmo, uma leitura criativa, como fizeram Ch. e L.; seja quando manifestam emoção no ato de ler poesias e projetá-las para sua vida privada, como fizeram as alunas do terminale littéraire (L) do lycée Marie Curie.

\section{As leituras poéticas criativas de Ch. E de 1 .}

Chamou-me a atenção um aluno do première économique et social (ES), do lycée Champollion, chamado aqui de Ch., que, em um simulado do bac oral, interpretou a seu modo o poema "Vénus Anadyomème", de Arthur Rimbaud. De acordo com Ch., Rimbaud fala, na primeira estrofe, de uma femme à cheveux bruns (verso 2) [mulher de cabelos castanhos] que está morta em un cercueil vert (verso 1) [caixão de zinco verde]. A professora, Mme. Blancard, indignada com tal interpretação tẫo inesperada, pergunta-lhe o que o levou a pensar nisso, e ele então completa que une vieille (verso 3) [uma velha] é, para ele - faz questão de frisar que se trata de uma interpretação dele - a imagem da morte! Risos generalizados. Ch. se justifica então dizendo que aquela imagem horrible (verso 10) [horrível] de une vieille (verso 3) [uma velha] com "[...] le col gras et gris, les larges omoplates / qui saillent; le dos court qui rentre et qui ressort; [...]" (versos 5 e 6) [a nuca gorda e cinza, as grandes omoplatas que saltam; o dorso curto que desce e sobe] era, na sua impressão, a imagem da morte! Mais risos.

E continuou a sua interpretação. Segundo o aluno francês, quando o poeta fala de "Puis les rondeurs des reins semblent prendre l'essor; / La graisse sous la peau paraît en feuilles plates" (versos 7 e 8 da segunda estrofe) [Depois a redondeza do lombo parece tomar a frente; a gordura sob a pele espalha-se em placas]; e em seguida, na terceira estrofe: "L'échine est un peu rouge, et le tout sent un goût / Horrible étranement; on remarque surtout / Des singularités qu’il 
faut voir à la loupe..." (versos 9, 10 e 11) [A espinha é um pouco vermelha e o todo rescende a um gosto horrível estranhamente; observa-se sobretudo singularidades que é preciso que se as veja sob lupa...]., o poeta está se referindo "às celulites daquela mulher”. Quanta criatividade!

Creio que as expressóes les reins [lombo/quadris] e l'anus [o ânus] no último terceto, contribuíram para levar Ch. a essa conclusão tão irreverente, mas que não deixa de esconder a imaginação e as fantasias sexuais do aluno adolescente. Nesse momento, a professora colocou a mão na cabeça e olhou para mim, com ar de desespero. Sinalizei que tudo bem, apesar de também estar surpresa com aquelas interpretaçóes. Ch. tentou mais uma vez justificar-se, dizendo, em tom de conclusão, que se tratava de um poema "sarcástico" e "obsceno", por isso Rimbaud usava aquelas expressóes.

Descontente, Mme. Blancard decidiu passar para a etapa seguinte do simulado, que consistia em fazer perguntas ao aluno acerca das características estilísticas e temáticas do poema de Rimbaud. Na décima e última questão, de fundo subjetivo, sinalizando assim o encerramento daquele exame oral, a professora perguntou a Ch.: "Quel est le poème qui t'a plu et pourquoi?” [De que poema você mais gostou e por quê?]. A resposta do aluno veio de imediato: "L’obscène" [Do obsceno]. Não houve tempo nem de responder ao "pourquoi", porque todos já estavam rindo - inclusive eu e a professora - da irreverência do aluno. A leitura de "Vénus Anadyomène" por Ch. foi pautada naquilo que lhe é, naturalmente, de interesse: a descoberta sexual. E em se tratando de um poema que se refere à Vênus mitológica, a associação não é de todo a se estranhar... Como assinala Petit (2002):

[...] uma importância muito particular na adolescência [...]; na qual se invadem as histórias lidas certamente com o desejo de se aproximar dos mistérios do sexo. [...] E hoje como ontem, muitos adolescentes folheiam avidamente os livros, porque estáo em busca de saber sobre questôes tabus, ou por darem acesso ao que possuem de mais secreto a dizer, por excelência, no domínio das fantasias eróticas, dos fantasmas. [...] Essa curiosidade é a própria base de uma pulsão de conhecimento - a psicanálise o mostrou - e ela os leva a buscar todas as direçôes, não somente nos manuais de educação 
sexual ou em livros de medicina, mas ainda em histórias em quadrinhos, testemunhos, biografias, ou na literatura erótica [...]. (PETIT, 2002, p. 50-51) ${ }^{13}$

E, pode-se acrescentar, também nas poesias. Foi o que o aluno Ch. fez. Para quem estava presente à aula, era evidente a atitude debochada do aluno, uma estratégia para se safar da seriedade exigida pela situação do exame simulado e também para se autoafirmar perante os outros colegas. Ch. queria ser engraçado, agir de uma maneira provocativa, um modo de se impor aos demais, de marcar sua identidade diante do grupo. É incompreendido por Mme. Blancard, que se envergonha da situação, afinal, de acordo com a lógica do sistema institucional, a escola não é um espaço para o "riso", para a "alegria" (Snyders, 1993); ao contrário, é o lugar da seriedade, do não prazer. Desse modo, a interpretaçáo do aluno do première torna-se incompreensível para a docente e, por extensão, para o lycée, pois se trata de uma leitura "desestabilizadora da ordem", de caráter essencialmente subjetivo.

É possível compreender, entretanto, por que para Ch. a sua interpretação faz sentido: é o seu universo, a sua fantasia (sexual), sua fase de vida que ele transporta para os versos do poeta Rimbaud. Na classificação de Rouxel (2004, p. 145-147), pode-se dizer que Ch. é um "lecteur spectateur" [leitor espectador], particularmente representativo entre os alunos do première; ou um "lecteur bohème" [leitor boêmio], diletante, amador, "flâneur", que usa o texto como pretexto para suas divagaçóes.

Esse aluno-leitor-espectador-boêmio do première do lycée Champollion (re)inventa o poema de Rimbaud sem se preocupar se está perto ou longe do projeto do autor do texto lido, aliás, sua interpretação pode até ser contrária a este. É nesse sentido que Ch. também individualiza sua leitura, subjetivando-

13 “(...) une importance toute particulière dans l'adolescence [...]; où l'on envahit les histoires lues, avec bien sûr, le désir d'approcher les mystères du sexe. [...] Et aujourd'hui comme hier, bien des adolescents feuillettent avidement des livres parce qu'ils sont en quête de savoir sur des sujets tabous, ou pour permettre à ce qu'ils ont de plus secret de se dire, par excellence dans le domaine des rêveries érotiques, des fantasmes. [...] Cette curiosité est la base même d'une pulsion de connaissance - la psychanalyse l'a montré - et elle pousse à chercher tous azimuts, non seulement dans les manuels d'éducation sexuelle ou les livres de médecine, mais encore dans des bandes dessinées, des témoignages, des biographies, ou de la littérature érotique, [...].» (tradução nossa) 
-a, como justifica S. Martin (2004, p. 204): “[...] o leitor torna-se sujeito de sua leitura porque inventa o poema de sua leitura por e no sujeito do poema"14.

$\mathrm{Na}$ definição de Langlade (2004, p. 85), Ch. comporta-se como um "leitor subjetivo", um "leitor pessoal, singular, normal" - adjetiva o autor -, bem diferente daquele "leitor experiente", também denominado por ele "leitor crítico, letrado, profissional" - eu diria, "ideal”, no sentido mesmo da "idealização" pretendida pela escola. E é por isso, ainda de acordo com Langlade (2004, p. 81), um leitor oprimido pelo sistema escolar:

A exclusão, ou ao menos a marginalização, da subjetividade do leitor é normalmente rotulada como uma condiçấo de êxito da leitura literária escolar e universitária. Um exemplo entre outros emprestado a um documento institucional recente: 'Para construir uma interpretação, é preciso ultrapassar as reaçôes pessoais, parciais e unilaterais, manchadas por erros, obscurecidas pelo jogo múltiplo das conotaçôes'. (Langlade, 2004, p. 81$)^{15}$

Nesse caso particular de Ch., a seleção subjetiva feita por ele ao expor sua interpretação do poema "Vénus Anadyomène" foi surpreendente, apesar de compreensível, dados os motivos já apontados. Por mais que saibamos que o texto literário é polissêmico por excelência, a professora não poderia concordar com aquela análise. Não se trata, portanto, de opressão (como diria Langlade, 2004) ou de castração (como diria Barthes, 2006), mas de orientação de leitura.

De acordo com Vincent Jouve (2004, p. 106), há dois planos considerados constitutivos do ato da leitura: "o plano afetivo" e o "plano intelectual", ambos afetados pela subjetividade.

14 “[...] le lecteur devenant sujet de sa lecture parce qu'il invente le poème de sa lecture par et dans le sujet du poème.» (tradução nossa)

15 "L'exclusion, ou tout au moins la marginalisation, de la subjectivité du lecteur est couramment affichée comme une condition de réussite de la lecture littéraire scolaire et universitaire. Un exemple parmi d'autres emprunté à un document institutionnel récent: 'Pour construire une intérpretation, il faut dépasser les réactions personnelles, partielles et partials, entachées d'erreurs, embrouillées par le jeu multiple des connotations'.» (tradução nossa) 
No plano afetivo, a identificação (que em princípio é programada pelo texto) é frequentemente vivida subjetivamente pelos leitores. Esse fenômeno está na origem de contrassensos, talvez conscientes deles mesmos [...]. Quanto ao plano intelectual, a compreensão (que está, no entanto, supostamente enraizada no sentido literal do texto) padece frequentemente da subjetividade dos leitores. É de início devido aos limites de nossa faculdade de memória: não podemos assimilar o conjunto de dados textuais; daí em diante, o que retemos de um texto depende prioritariamente de nossos centros de interesse. Essa seleção subjetiva da informação é a fonte de numerosos erros de leitura. (JOUVE, 2004, p. 108) ${ }^{16}$

Creio que o equívoco de Ch. se deu tanto no "plano afetivo" quanto no "plano intelectual". O aluno fez uma leitura consciente, a fim de se fazer engraçado para os outros colegas, para mim e também para a professora. Foi um episódio em que a recepção subjetiva do poema foi deturpada de acordo com os interesses do aluno adolescente.

No Brasil, presenciei outro momento epifânico de interpretação, dessa vez, na classe do terceiro ano do ensino médio da escola pública estadual (Colégio C) em que estive presente. A professora da turma (P3) preparou uma aula introdutória sobre o Modernismo e escolheu, como chamariz para aquela temática, trabalhar com o poema de Waly Salomão, Remix do século XX, cantado na voz da intérprete Adriana Calcanhoto. Os alunos estavam eufóricos com a novidade e logo quiseram saber do que se tratava aquele título. $\mathrm{O}$ aluno R. adiantou-se para explicar que "remix" seria uma espécie de "resumáo" do século XX. Entra em cena o aluno L., que retruca explicando que "remix" na música é uma mistura de sons e ritmos, que tornam a música "remixada".

16 "Sur le plan affectif, d'identification (qui en principe est programmée par le texte) est souvent vécue subjectivement par les lecteurs. Ce phénomème est à l'origine de contresens, parfois conscientes d'eux-mêmes [...]. Concernant le plan intellectuel, la compréhension (qui est, pourtant, censée s'enraciner dans le sens littéral du texte) pâtit souvent de la subjectivité des lecteurs. C'est d'abbord dû aux limites de nos facultés mémorielles: nous ne pouvons assimiler l'ensemble des données textuelles; dès lors, ce que nous retenons d'un texte dépend prioritairement de nos centres d'intérêt. Cette sélection subjective de l'information est la source de nombreuses erreurs de lecture." (tradução nossa) 
Após as preliminares, a professora "solta o play" da música e os alunos demonstram curti-la com expressôes do tipo: "Nossa, que da hora!". Riem do verso "buceta" e ficam atentos para os outros versos, tentando compreender palavra por palavra - afinal, estão acostumados a decodificaçóes! A partir de então, o aluno aqui chamado de L. tomou a vez e a voz para interpretar a letra do poeta baiano à sua maneira, subjetivamente. E P3 deixou-o à vontade, balançando a cabeça positivamente, sem se preocupar se a leitura de L. estava "correta ou náo". Estava feliz porque seus alunos aprovaram a ideia de começar o tema das "vanguardas europeias" por meio de uma música popular.

L. entâo deslanchou: disse que "bolchevique" era uma palavra que eles tinham estudado na aula de história; que "sputinik" era a nave que "supostamente" levou o homem à lua; que "motosserra" seria uma crítica à devastaçáo florestal, responsável pelo aquecimento global; que "clonagem" seria uma referência ao clone, provavelmente ao da ovelha Dolly; que "antivírus" expressa a luta contra os vírus que surgem a cada momento, como o HIV; que "polivox" e "fônico", nos versos finais, poderiam ter a ver com a "nave louca" e finaliza atentando para o ritmo da música, segundo ele, "um rimo rápido, sem parar, corrido, como se fossem batidas do coração"; percebe que a música toda tem a mesma batida, e diz que isso prende o ouvinte; por fim, conclui que este é o ritmo do século XX, daí o título fazer referência a um "remix".

A professora ficou tấo feliz com as interpretaçôes do seu aluno que disse ao final da aula que tinha vontade de dar um "beijo na boca" dele! (Risos). Os demais alunos também pareciam gostar daquelas análises e, eventualmente, interrompiam para indagar a $\mathrm{P} 3$ alguns versos ou palavras que não compreenderam, tais como: o que seria "babilaque", "Sagarana", "jogo linguístico", "Dada". Este último serviu de mote para a professora antecipar algo sobre o "Dadaísmo".

Como se vê, nem sempre as interpretaçôes dos alunos funcionam como "deboche" ou "desvio" da aula. Na sua leitura subjetiva, L. demonstrou autonomia, fez relaçôes interdisciplinares, ousou e se saiu bem. Compartilho, portanto, com Nathalie Brillant Rannou (2010), a ideia de que a escola deve promover esse tipo de leituras subjetivas "que concorrem para o desenvolvimento do aluno como pessoa, que deixam um lugar pleno para a expressão e a realidade do sujeito". (Rannou, 2010, p. 22) ${ }^{17}$.

17 “qui concourent au développement de l'élève en tant que personne, laissent une place entire à l'expression et la réalité du sujet.» (tradução nossa) 
Vale dizer que, no Brasil, somente na escola pública observei os alunos assumirem sua voz interpretativa na leitura de poemas em classe. Nas escolas particulares em que realizei a pesquisa de campo, os alunos não se arriscaram a fazer interpretaçóes, sempre aguardavam a voz dos professores para ler em voz alta os poemas e interpretá-los. Foi também na escola estadual que ouvi dos alunos duas pérolas na definição do que entendem por poético: segundo o aluno R., "poema é você expressar o que você pensa”, e para L., "poesia é como mulher: a gente nunca entende por completo". De fato!

E para que se (re)afirme a possibilidade de se desenvolver em um ambiente escolar uma leitura subjetiva, emancipadora, capaz de nos libertar, de nos fazer transgredir; uma leitura que nos leve a elaborar nossa cidadania, a conquistar nossa posição mesma de sujeitos, nossa interioridade, nosso espaço, consciente/ inconsciente, na construção de um sujeito-leitor; encerro estas reflexôes relatando o que observei em uma classe de terminale littéraire no lycée Marie Curie, e que me faz acreditar, em comum acordo com Petit (2002, p. 99), no papel da literatura - e das poesias como extensão - como "leituras reparadoras".

\section{A leitura subjetiva das poesias de Philippe Jaccottet}

Por fim, relato aqui o que observei em uma classe de terminale, na França. Para aquela turma, Mme. Gardey propôs a leitura da obra poética $\grave{A}$ la lumière d'hiver, de Philippe Jaccottet, livro cobrado pelo exame escrito do $b_{a c}{ }^{18}$. A leitura prévia deveria ser feita em casa e nas dinâmicas de classe, Mme. Gardey solicitava que cada aluno lesse um poema em voz alta e, em seguida, fazia-se uma discussão interpretativa e analítica das poesias, a fim de traçar as principais temáticas trabalhadas pelo poeta em seus textos.

Os alunos participavam ativamente das leituras e dos comentários pós-leitura poética, o que muito me impressionou. Conforme a leitura se realizava, mais denso ficava o clima na classe, provavelmente em função da temática central da obra: a morte. Jaccottet, na primeira parte do livro ("Leçons"), lamenta a perda do seu mestre, do seu discípulo - forma como se refere ao

18 É importante dizer que, nas escolas em que realizei a pesquisa, tanto na França quanto no Brasil, as leituras literárias propostas pelos professores eram sempre de obras cobradas pelos vestibulares aqui e pelo bac lá. Lamento que sejam as avaliaçóes que determinem os currículos e as dinâmicas de leitura em sala de aula. 
seu sogro, então vítima do câncer. A natureza mórbida, o corpo doente, o sofrimento latente nos versos do poeta à procura de descrever esse sentimento inexplicável que é a dor da perda, sobretudo quando esta se dá pela morte, angustia toda a classe: a mim, aos alunos e à própria Mme. Gardey. Todos estávamos envolvidos com as leituras poéticas.

Em um determinado momento da aula, uma aluna, visivelmente emocionada, levanta-se de sua carteira e pede permissão para sair. Mme. Gardey concede-lhe alguns minutos lá fora e a aconselha a voltar quando estivesse melhor. Clima tenso e as leituras poéticas continuam. Dez minutos se passam e outra aluna solicita permissão para sair em socorro da colega que não voltava. A professora agradece-lhe a gentileza e as duas alunas ficam fora de sala de aula por quase meia hora, voltando quase ao final da aula. Mme. Gardey lhes pergunta se está tudo bem e elas respondem balançando a cabeça positivamente. Toca o sinal e todos os alunos saem para o intervalo. Eu, curiosa, chego junto à professora que guardava seu material e logo lhe pergunto o que tinha ocorrido com aquelas duas alunas. Foi entấo que Mme. Gardey me explicou que a primeira tinha o pai com câncer e a segunda tinha a mãe em estágio terminal da doença. Eis a poesia, em seu exercício ético e estético, capaz de tocar o corpo e, por extensão, a alma, diria Jean-Luc Nancy (2006). Seria possível afirmar que os textos poéticos de Jaccottet foram capazes de tocar os sentimentos daquelas alunas, despertando-lhes dor? Ou elas, já tão submersas em sua dor, apenas se deixaram transbordar quando leram o poeta?

Ou ainda, sob outra perspectiva, talvez mais cruel: ao se retirarem da sala de aula emocionadas, aquelas alunas estariam, de certa forma, sendo excluídas pela própria instituição escolar, uma vez que se viram obrigadas a se ausentarem da classe para não perturbar os outros com sua dor? Se a escola não é o espaço do "riso" nem da "alegria", como já dito, tampouco é o espaço do "choro", da "dor", da "morte”. Nesse ambiente, tem-se a impressão de que é preciso se conter o tempo todo, pois o extravasar pode não ser bem visto nem bem recebido pelos demais. É a escola se construindo como o lugar do silêncio, do ficar calado e do se retirar para sufocar a própria dor.

Contudo, se não encontram respaldo no ambiente escolar, as alunas podem encontrar consolo nas leituras literárias. Acredito que, de alguma forma, a leitura poética de Jaccottet funcionou para elas como uma leitura reparadora, acolhedora, autoterapêutica - como bem adjetiva Petit (2002) - aquela que nos socorre em momentos de crise: 
Ao longo de toda a vida, nos momentos de crise, a leitura pode ser uma via privilegiada para nos fazer encontrar um espaço repousante e a experiência da criança que, a partir desse espaço estético, calmo, protetor, entre sua mãe e ela, encontra forças e se torna autônoma. Se ela permite descobrir-se ou construirse, ela se torna crucial quando é preciso reconstruir-se após um luto, uma doença, um acidente, uma separaçáo amorosa, a perda do emprego, uma depressão, todas as experiências de que nossos destinos são feitos, todas as situaçóes que maltratam a representação que se tem de si e o sentido de sua vida. A leitura exerce agora o papel de autoterapia. (PETIT, 2002, p. 100) ${ }^{19}$.

As alunas podem ter reconhecido sua dor na dor do poeta que, inconformado, sofre com a perda de seu sogro, assim como elas sofrem com a proximidade da morte dos pais. A leitura das poesias de Jaccottet pode permitir que as alunas elaborem ou restaurem o seu espaço íntimo, a sua individualidade, ajudando-as a resistir à fragilidade física e psíquica em que se encontram. Pela leitura literária e através dela, podem (re)conquistar sua posição de sujeito, sua dignidade, sua condição humana, um trabalho quase psicanalítico na superação da dor e, portanto, na (re)construção de si.

Não que a leitura poética, no caso, possa tudo reparar (seria ingênuo acreditar nisso, reconhece Petit), "mas às vezes contribuir para simbolizar suas pulsóes destruidoras, elaborar seu pensamento, dar uma maior liberdade para se portar além dos caminhos inteiramente traçados pelo destino"20 (PETIT, 2002, p. 10).

19 "Mais tout au long de la vie, dans le moments de crise, la lecture peut être une voie privilégiée pour nous faire retrouver un espace paisible et l'expérience de l'enfant qui, à partir de cet espace esthétique, calme, protecteur, entre sa mère et lui, se ressource et devient autonome. Si elle permet de se découvrir ou de se construire, elle devient cruciale lorsque l'on doit se reconstruire, après un deuil, une maladie, un accident, une séparation amoureuse, le perte de son emploi, une dépression, toutes épreuves dont nos destins sont faits, toutes situations qui mettent à mal la représentation que l'on a de soi et le sens de sa vie. La lecture joue alors le rôle d'autothérapie. " (tradução nossa)

20 "mais parfois contribuer à symboliser ses pulsions destructrices, à élaborer sa pensée, à donner une plus grande liberté pour se porter ailleurs que sur les chemins tout tracés par le destin. " (tradução nossa) 
De fato, a recepção da leitura de Jaccottet nessa classe de terminale littéraire sensibilizou a todos - eis um événement poétique [evento poético], no sentido atribuído por Nathalie Rannou (2010). Acredito que promover essa leitura literária, poética, subjetiva entre os alunos adolescentes seja uma travessia ${ }^{21}$ para os professores da Educação Básica; contudo, um desafio possível tanto no Brasil quanto na França, pois acredito, juntamente com Paul Zumthor (2007, p. 81), que "minha leitura poética me 'coloca no mundo' no sentido mais literal da expressão".

Retomando, por fim, os dizeres da epígrafe que abre este artigo, foi através da leitura subjetiva dos poemas de Jaccottet que as alunas do terminale a que me referi puderam (se) ler, (se) dizer, (se) escrever, ambas e cada qual na sua dor.

\section{Referências}

BARTHES, ROLAND. O Prazer do Texto. Trad. J. Guinsburg. São Paulo: Perspectiva, 2006.

CHARTIER, Roger. A ordem dos livros: leitores, autores e bibliotecas na Europa entre os séculos XIV e XVIII. Trad. de Mary del Priore. Brasília: Ed. Universidade de Brasília, 1994.

COSSON, Rildo. Letramento Literário: teoria e prática. São Paulo: Contexto, 2006. COSSON, Rildo. A prática de letramento literário na sala de aula. In: Gonçalves, A. V. e PINHEIRO, A. S. (orgs.) Nas Trilhas do Letramento: entre teoria, prática e formaçáo docente. Campinas: Mercado das Letras, 2011, p. 281-297.

DURÃO, Fábio Akcelrud. A crise nos estudos literários, hoje. In: Signorini, Inês e Fiad, Raquel (orgs). Ensino de língua: das reformas, das inquietaçóes e dos desafios. Belo Horizonte: Editora Ufmg, 2012, p. 191-202.

FONTES, Joaquim Brasil. As obrigatórias Metáforas: apontamentos sobre literatura e ensino. São Paulo: Iluminuras Ltda., 1999.

FOUCAULT, Michel. A ordem do discurso. Tradução de Laura Fraga de Almeida Sampaio. 14ª ed. São Paulo: Loyola, 2006.

GEBARA, Ana Elvira Luciano. A poesia na escola: leitura e análise de poesia para crianças. São Paulo: Cortez, 2002.

HOUAISS, Antônio; Villar, Mauro. Dicionário Houaiss de Lingua Portuguesa. Rio de Janeiro: Objetiva, 2001, p. 1.152.

21 “Tomo emprestado o termo "travessia” à maneira de João Guimarães Rosa. 
JACCOTTET, Philippe. À la lumière d'hiver (1977). Précedé de Leçons et de Chants d'en bas (1983) et suivi de Pensées sous les nuages (1994). Éditions Gallimard, 1994.

JOUVE, Vicent. La lecture comme retour sur soi: de l'intêret pédagogique des lectures subjectives. In: Rouxel, Annie; Langlade, Gérard. Le sujet lecteur: lecture subjective et enseignement de la littérature. Presses Universitaires de Rennes, 2004, p. 105-114.

LANGLADE, Gérard. Le sujet lecteur auteur de la singularité de l'oeuvre. In: Rouxel, Annie; Langlade, Gérard. Le sujet lecteur: lecture subjective et enseignement de la littérature. Presses Universitaires de Rennes, 2004, p. 81-91.

MARCUSCHI, Luiz Antônio. Gêneros textuais no ensino de Língua. In: Produção textual, análise de gêneros e compreensão. São Paulo: Parábola Editorial, 2008, p. 146-225.

MARTIN, Marie-Claire \& Martin, Serge. Les poésies, l'école. 1er. édition. Paris: Presses Universitaires de France, 1997, p. 138.

MARTIN, Serge. Irréversible, imprévisible petite histoire d'un chroniqueur en poésie contemporaine. In: Rouxel, Annie; Langlade, Gérard et al. Le sujet lecteur: lecture subjective et enseignement de la littérature. Rennes: Presses Universitaires de Rennes, 2004, p.197-205.

MOITA LOPES, Luiz Paulo da. Pesquisa interpretativista em Linguística Aplicada: a linguagem como condição e soluçáo. In: Revista de Documentação de Estudos em Linguística Teórica e Aplicada (d.e.l.t.a). vol. 10, n 2, 1994, p. 329-338.

NANCY, Jean-Luc. Corpus. Paris: Éditions Métailié, 2006.

NEVES, Cynthia Agra de Brito. A literatura no ensino médio: os gêneros poéticos em travessia no Brasil e na França. 2014. 884p. Tese (Doutorado em Linguística Aplicada) - Instituto de Estudos da Linguagem, Universidade Estadual de Campinas, Campinas, 2014.

PETIT, Michèle. Éloge de la Lecture - la construction de soi. Éditions Belin, 2002.

RANNOU, Nathalie Brillant. Le Lecteur et son poème. Lire en poésie: experience littéraire et enjeux pour l'enseignement du français en lycée, thèse de doctorat présentée à la faculté des Arts, Lettres, Langues de l'Université de Rennes 2, 2010.

ROJO, Roxane Helena Rodrigues. Gêneros do discurso e gêneros textuais: questōes teóricas e aplicadas. In: Meurer, José Luiz; Bonini, Adair; MottaRoth, Désirée (orgs.). Gêneros: teorias, métodos, debates. São Paulo: Parábola Editorial, 2005, p. 184-207. 
ROJO, Roxane Helena Rodrigues (orgs). Gêneros discursivos do círculo de Bakhtin e multiletramentos. In: ROJO, Roxane Helena Rodrigues. Escol@Conectada: os multiletramentos e as TICs. São Paulo: Parábola, 2013, p. 13-36.

ROUXEL, Annie. Autobiografie de lecteur et identité littéraire. In: Rouxel, Annie; Langlade, Gérard et al. Le sujet lecteur: lecture subjective et enseignement de la littérature. Rennes: Presses Universitaires de Rennes, 2004, p. 137-152.

SCHNEUWLY, Bernard; Dolz, Joaquim (e colabs.). Gêneros orais e escritos na escola. Trad. e org. Roxane Rojo e Glaís S. Cordeiro. Campinas, SP: Mercado das Letras, 2004.

TODOROV, Tzvetan. A literatura em perigo. Trad. Caio Meira. Rio de Janeiro: Difel, 2012.

ZUMTHOR, Paul. Performance, recepção, leitura. Trad. Jerusa Pires Ferreira e Suely Fenerich. São Paulo: Cosac Naify, 2007.

SNYDERS, Georges. Alunos Felizes - reflexão sobre a alegria na escola a partir de textos literários. Trad. Cátia Ainda Pereira da Silva. Rio de Janeiro: Paz e Terra, 1993.

\title{
POETIC READINGS IN THE CONSTRUCTION OF HIGH SCHOOL STUDENTS' SUBJECTIVITY
}

\begin{abstract}
This paper analyzes practices of reading poetry aloud in high school classes both in Brazil and in France. By enabling themselves to be affected by such readings, students (re)discover their subject position, their dignity, their human condition, and their social responsibility in a quasi-psychoanalytic work of (re)construction of the self. In short, by reading, saying and writing (themselves), students place themselves in the world.
\end{abstract}

KEYWORDS: literary literacy; poetic genres; subjective reading.

Recebido em: 30/10/2015

Aprovado em: 21/01/2016 